\title{
Design, measurement, and characteristic analysis of uncertainty indices for education fiscal policies: a case study of China
}

\author{
Dong Wang ${ }^{1}\left(\mathbb{D} \cdot\right.$ Jingxuan Fang $^{1}$ (i) $\cdot$ Qiqi Zhang $^{1}$ (D)
}

Received: 29 October 2020 / Revised: 2 March 2021 / Accepted: 6 April 2021 / Published online: 20 April 2021

(c) Education Research Institute, Seoul National University, Seoul, Korea 2021

\begin{abstract}
Since the release of "4\%" objective of fiscal educational expenditure to GDP in 2012, the Chinese governments at all levels have frequently formulated or changed education finance policy in light of the complex situation of China's economic development. The policy changes have ensured the steady growth of education financial investment, but also brought a series of unknown or uncertain factors to the allocation of educational resources. According to the text context from the selected mainstream Chinese media in the past two decades, this study creates a newspaper-based policy uncertainty indices of China's education fiscal policy under the framework of Baker (JAMA 131(4):1593-1636, 2016)'s study. We also apply the EGARCH model to test the robustness of the results. Our findings reveal that the uncertainty indices are highly consistent with the fluctuation of education fiscal policy in various stages in China. It suggests that the government sectors should define the reasonable boundaries of the "tangible hand" and harden the budget in the process of allocating education resources, to eliminate the negative impact brought by the uncertainty of education fiscal policy. Moreover, this study puts forward the research prospect of the application of policy uncertainty in the field of education.
\end{abstract}

Keywords Education finance $\cdot$ Policies $\cdot$ Uncertainty $\cdot$ Design of indices

\section{Introduction}

Education is the cornerstone and foundation of the country. China's "Nineteenth National Congress" report clearly stated that people should give priority to education then make education develop with fair and quality. In this "New Era", ${ }^{1}$ China's economic development is in a complicated situation called "three-phases superposition" ${ }^{2}$ which includes a shifting period of economic growth rate, painful period of structural adjustment and digestive period of early stimulated policies. To stabilize the strategic position of priority of development of education, government departments at all levels need to increase investment in education and maintain a steady increase in education funding then implement

Qiqi Zhang

657189677@qq.com

Dong Wang

shuimuwd@126.com

Jingxuan Fang

942719331@qq.com

1 School of Public Administration, Nanjing University of Finance \& Economics, Nanjing 210023, China education financial policies that meet the requirements of the "New Era" eventually. In this respect, China's education fiscal policy changes more frequently to achieve this goal. As a result, while promoting the development of education, it also brings a series of unknown uncertainties to the allocation of government education resources.

The "Uncertainty" refers to clarity, or lack thereof, about future economic activity. It incorporates both "risk" and "Knightian uncertainty" (Angus, 2017; Frank, 2006). In this article, we hold that the uncertainty of educational fiscal policy should refer to the uncertainty problems caused by the government policies which have a direct or indirect influence on all kinds of educational activities of the whole society, such as the government, the school, the teacher, the family and even the educatee, especially those education finance policies with difficult future trends, strengths or effects which are hard to be accurately predicted. At the same time, it should include two levels of meaning: on the one hand, it includes uncertainty about the frequent changes

\footnotetext{
${ }^{1}$ In October 2017, China's "Nineteenth National Congress" report clearly stated that Chinese socialism has entered a "New Era".

2 After the 18th Party Congress, President Xi Jinping made "threephases superposition" judgments on China's economic situation.
} 
in the content of educational fiscal policy or the unpredictable future direction. On the other hand, it includes the unpredictability of the implementation intensity or implementation effect of the education fiscal policy of uncertainty. For example, in a period of time, if the government frequently make or change the educational fiscal policy, the uncertainty indices of education fiscal policy will increase.

The uncertainty of education fiscal policy is the potential cost of the government in the process of allocation of educational resources. Therefore, the research and effective management of the uncertainty problem can reduce the potential cost of the policies, thus greatly improve the efficiency of the implementation of educational finance policies. Consequently, based on the course of the changes in China's education fiscal policy in the past two decades, this work constructs the uncertainty indices of Chinese educational financial policies and carries out the robustness test and characteristic analysis by synthesizing the calculation method designed by scholars such as Baker and Bloom to provide a theoretical basis for exerting the function of the automatic stabilizer which is assigned to educational finance policies and educational finance in the process of flexible choice and ironing out the uncertain impact of the macroeconomic cycle.

\section{Background}

\section{The current situations of educational development and funding}

During the 70 years after the founding of the People's Republic of China, China's education undertakings have made remarkable progress and have entered the era of highlights with the promotion of various education and financial policies. As of the end of 2018, China had a total of 589,900 schools at various levels and types with 276 million students and 16.73 million full-time teachers. The level of the spread of education at all levels has continued to improve and the opportunities of being educated for citizens have been further expanded. Among them, for the pre-school education period, there were 266,700 kindergartens across China and the gross enrollment rate increased sharply from $14 \%$ in the early 1950 s to $81.7 \%$, thus realizing a leap that is from existence to excellence. During the stage of compulsory education, the total number of students enrolled in junior and primary schools nationwide is 150 million after adding up. The primary school net enrollment rate increased from $20 \%$ in the early days of the founding of China in 1949 to 99.95\% while the junior high school gross enrollment rate also increased from $3.1 \%$ to $100.9 \%$. For the stage of upper secondary education, there are 24,300 schools nationwide, and the gross enrollment rate increased from $1.1 \%$ in 1949 to $88.8 \%$, which symbolized that the education in China is about to enter the stage of popularization. In the higher education stage, there are 2,663 ordinary colleges and universities in China, and the gross enrolment rate has been raised from $0.26 \%$ in the early days of the founding of China to $48.1 \%$ and it has totally entered the stage of popularization at that time. ${ }^{3}$

As an important part of public financial expenditure, education financial investment is an indispensable material basis for the development of education. In 2018, China's total investment in education funds was 4,613.5 billion yuan, of which 3.699 billion yuan was fiscal educational expenditure. It was such an increase of $8.13 \%$ over the same period last year, besides accounting for 4.11 per cent of the GDP share of the year and 16.74 percent of the financial expenditure. From the perspective of the growth of budgetary educational expenditure per student, compared with 2012, the average increase of budgetary educational expenditure per student of primary schools, junior middle schools, senior high schools and colleges in 2018 was $84.83 \%, 102.71 \%, 111.51 \%$ and $35.92 \%{ }^{4}$ Finally, the strategic target of 4 percent of financial investment in education ${ }^{5}$ have achieved and exceeded for seven consecutive years after 2012, as presented in Fig. 1.

On the other hand, it can be seen that the growth of China's fiscal education funds began to show signs of weakness with the expansion of the "three-phase superimposition" of the Chinese economy in the new era from Fig. 1. For the first time, China's fiscal educational expenditure reached 2.22 billion yuan in 2012, which reached and exceeded $4 \%$ of GDP proportion with a nominal increase of $19.64 \%$ over the same period last year. However, the growth rate fell to $8.13 \%$ in 2018. At the same time, after the release of the "policy objective" of "4\%" of financial investment in education, the proportion of fiscal educational expenditure in major economic indices also fell sharply. In 2018, the proportion of fiscal educational expenditure in the GDP fell from $4.28 \%$ in 2012 to $4.11 \%$, which approached the lowest value in nearly seven years. Meanwhile, its proportion of fiscal expenditures has also correspondingly declined to $16.74 \%$. Both accounts

\footnotetext{
3 The data are compiled from the National Statistical Bulletin of Education Development in 2018 released by the Ministry of Education in July 2019.

4 The data are compiled from the National Statistical Bulletin of the Implementation of Education Funding in 2018 released by the Ministry of Education in October 2019.

5 In February 1993, the Chinese central government issued "The Outline of Educational Reform and Development in China"and required an increase of fiscal educational expenditure, with a target to reach $4 \%$ of its GDP by the end of the 20th Century. As a strategic document in China's education reform and development, "The Outline"aligned education investment with the country's economic development for the first time in its history, and provided quantitative targets as performance measurement and evaluation.
} 


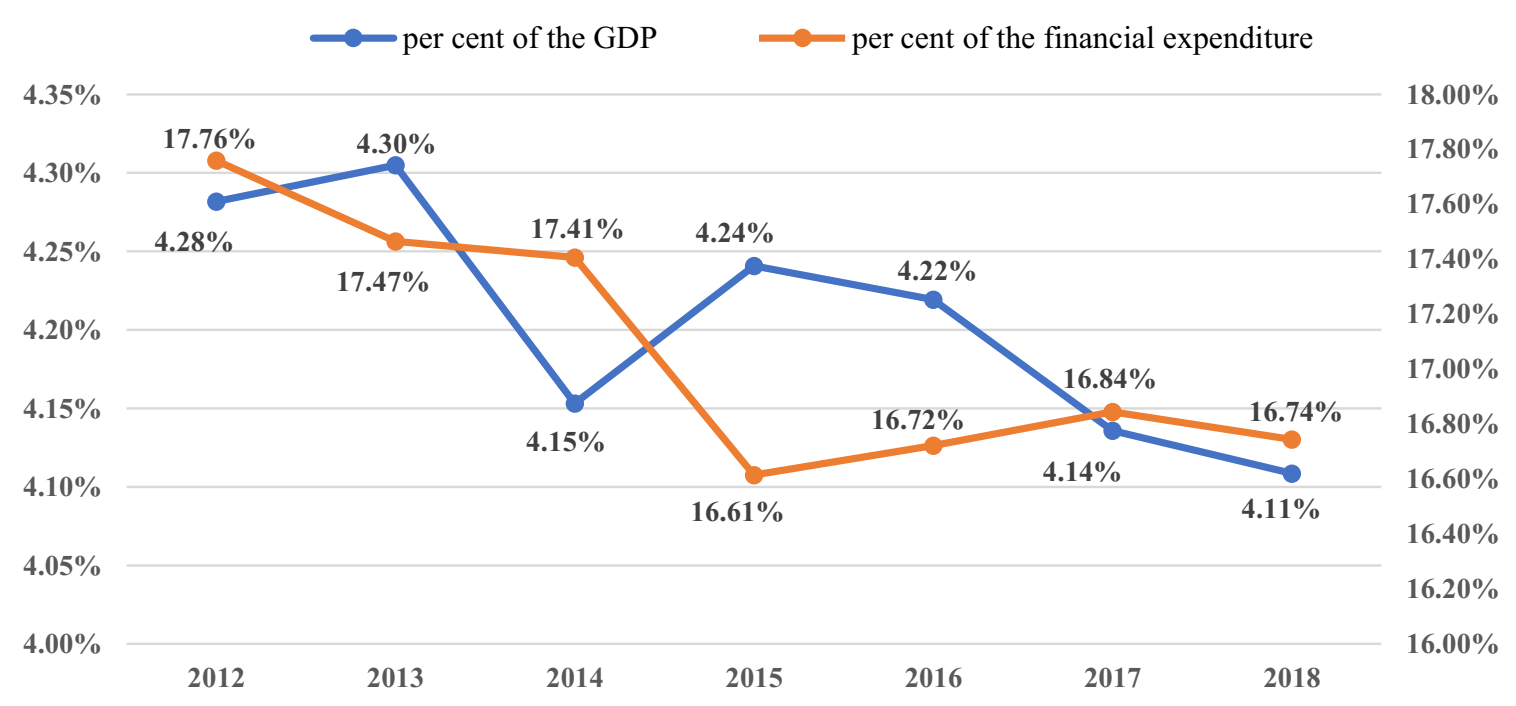

Fig. 1 Trend chart of China's fiscal educational expenditure ratio

showed a trend of fluctuating decline in the overall proportion during the seven years. Consequently, the education financial policies are facing an embarrassing situation in the "post 4\%" era.

\section{The choice of education Fiscal policies in the "post $4 \% "$ era}

Government finance is the material foundation of national governance while scientific and reasonable education finance policies is an institutional guarantee for maintaining education equity, optimizing resource allocation and promoting the development of national education. In the "post 4\%" era of education finance, how to choose and perfect the education financial policies and how to ensure the sustained growth of education funds based on consolidating the achievements have become urgent problems to be addressed. ${ }^{6}$

In response to this problem, the central and local governments have frequently formulated a series of education fiscal policies which are based on the principles of "preserving basics, keeping the bottom line, making up for shortcomings and promoting fairness" in recent years. The frequent formulation or change of the policy has a certain impact on the China education fiscal policy fluctuation. In January 2017, the State Council issued the Thirteenth Five-Year Plan for National Education Development, which requires priority protection of education financial investment and insists that its share of GDP is not less than 4\%. Subsequently, in August

\footnotetext{
6 Yuan, G.R. (2013). Address to the National Conference in 2013 on Education. China Education News, 25 January, 1st Edition.
}

2018, the State Council issued Opinions on Further Adjusting and Optimizing the Structure to Improve the Efficiency of the Use of Education Funds, which adheres to the principle of "giving priority to its protection and increasing the investment" for education financial investment requirements. One the other side, it also emphasizes the basic requirement that its proportion is not able to be less than $4 \%$. In February 2019, the CPC Central Committee and the State Council issued the China Education Modernization 2035, which called for the perfection and improvement of the long-term mechanism for the support and growth of educational financial investment and once again reiterated the requirement of not less than 4\%. In addition, as early as November 2013, the Decision on Certain Major Issues of Comprehensive and Deepening Reform which was considered and adopted at the Third Plenary Session of the 18th Central Committee stipulated that key expenditures generally do not adopt linked input methods, and gradually clear and standardize matters which are related to the key expenditures linked to GDP or fiscal revenue and expenditure growth. However, investment in education finance ranks first among various linked expenditures. The emergence of the situation which is completely opposite to the policies' objectives in the process of the formulation and implementation of education financial policies and macroeconomic policies have further aggravated uncertainty of future policies.

\section{The focus of the uncertainty of education fiscal policies}

Education finance policies are an important issue in the field of education economy and management while it is also a vital tool and means for the country to carry out the 
allocation of educational resources. It is one of the focuses of the theoretical and practical departments. A scientific and reasonable education financial policy is the system's guarantee for maintaining education equity, optimizing resource allocation and promoting the development of national education. The current academic research on education finance policies mainly aims at the qualitative interpretation of the policy itself, the comparison of China and abroad or the correlation and the causality's analysis of policy effects and the focus on the policies' uncertainty after ignoring the change of educational financial policies as well. China's education fiscal policies have climbed to the maximum value of policy benefits after decades of changes. Besides, the "4\%" investment policy also released the largest "policy dividend" in 2012, and the education finance investment was approaching the "Pareto optimal" State. ${ }^{7}$ The uncertain issues caused by the recent frequent changes in education fiscal policies can better measure the effectiveness of policies' implementation compared with the policies tools themselves (Fatas \& Mihov, 2013). As a result, in the process of researching the allocation of resources, the academic community and even the government ought to pay attention to the uncertainty caused by policies changes at the same time instead of only focusing on the content changes at the level of education or economic policies.

\section{Literature review}

The measurement of policy uncertainty indices is the main basis for the study of uncertainty, and it is also the foothold of empirical research on policy fluctuations. At present, the measurement of policy uncertainty in academic circles is mainly divided into three methods: first, the method of regression model's measurement which is based on economic indices; second, the method of keyword's capture that is based on media information; finally, the method of questionnaire interview which is based on behavioral subjects.

\section{The method of regression model's measurement which is based on economic indices}

On the one hand, some scholars selected proxy variables for fiscal or monetary policies' fluctuations then constructed regression models and took the standard deviation of the estimated residual terms as the indices to measure the policy uncertainty problems. For instance, scholars such as Marion and Ali (2005) established first and second-order

\footnotetext{
${ }^{7}$ Wang, F.Y., Cai, Q.Y., \& Tan, M.J. (2018). Education Finance Investment Promotes Urbanization of People. China Education News, March 1, 7th edition.
}

autoregressive models based on fiscal expenditure data and used the standard deviation of the residuals which is estimated by the autoregressive model as an index to measure the uncertainty of fiscal policy. In addition, Albuquerque (2011) and Anzuini (2015) and other scholars also used fiscal expenditure and other data as dependent variables to construct a policy response function and took the standard deviation of the residual items estimated by the model as an index to measure the uncertainty of fiscal policy. Meanwhile, Born (2014) selected the proxy variables of fiscal and monetary policies to builds a time sequence model and used the time-varying standard deviation that is estimated after the estimate of model regression as a measure of economic policy uncertainty.

On the other hand, some scholars constructed a generalized autoregressive conditional heteroscedasticity model (GARCH) and used the estimated coefficients or conditional heteroscedasticity as an index to measure the problem of policy uncertainty. In this respect, Fatas (2013) measured the fiscal policy uncertainty index by using the GARCH model while Wang et al. (2015) used the GARCH model to calculate the Beijing local fiscal uncertainty indices. Lastly, Bloom (2014) also used the GARCH model for quantitative analysis of industrial added value and other macroeconomic indices then took the estimated conditional heteroscedasticity of total output as a measure of economic policies' uncertainty.

Finally, some scholars constructed the vector autoregressive models based on macroeconomic panel data and then quantified the regression coefficients as indices to measure the policy uncertainty. Based on nearly 100 kinds of macroeconomic time sequence data, Jurado et al. (2015) included all of them into the economic forecast model thus to obtain the conditional volatility of the forecast deviation of each economic variable. Finally, it was weighted and averaged to construct the JLN policy uncertainty indices. Scholars such as Gong et al.(2018) divided taxation policies into three parts including responsiveness, continuity and flexibility which were all based on data of local tax revenue, enterprise income tax and goods and services tax in 284 prefecture-level cities in China from 2004 to 2013. Eventually, a panel vector autoregressive model was constructed to estimate the uncertainty index of different tax policies in prefecture-level cities of China.

\section{The method of keyword's capture that is based on media information}

When a policy has an impact on the decision-making of economic actors, the earliest and most direct channel for the public to obtain policy information comes from the news media. In the era of big data, the influence of media information data on market economic actors is becoming more and 
more important, therefore it can be used to measure policy uncertainty.

For example, by grabbing the number of articles containing the vocabularies of economy, uncertainty and a series of similar vocabularies from the New York Time every month, conducted text process and analysis and construct an economic policy uncertainty index (Alexopoulos and Cohen 2009). Moreover, Baker et al. (2016) further expanded the sources of media information on the basis of Alexopoulos and other scholars then selected the 10 most influential newspapers in the United States, such as The Wall Street Journal, The New York Times and USA Today. Through grabbing the number of articles which contains economic, policy and uncertain vocabularies, the economic policy uncertainty index (EPU) is formed after the process of standardization. At present, Baker's research team expands the scope of the research further, which contains tracking and measuring of the economic policies uncertainty indices of major economies all around the world including Canada, Germany, Russia and China. The indices are released after they are compiled according to the statistics of mainstream media in various countries and has been widely recognized. Finally, it became one of the most influential economic policies uncertainty indices in academia. Besides, three scholars including Steven et al. (2019) focused their research on China and selected Guangming Daily and People's Daily, the two most influential newspapers in China. Furthermore, they grabbed the frequency of occurrence of the words "economics", "policy" and "uncertainty" in their published articles and carried out weighted standardization treatment. In accordance with the three stages of "central planning period", "reform and opening period" and "globalization period", China's monthly economic policy uncertainty indices since 1949 and the annual trade policies uncertainty indices since 2000 has been developed eventually.

\section{The method of questionnaire interview which is based on behavioral subjects}

Apart from the process of calculating policies uncertainty through the methods of the regression model and keyword's capture, some scholars try to measure the prospects of future economic policies according to the behavior subjects.

Take Chong and Gradsteing (2009) for example. Chong designed the questionnaire whose score is assigned from 1 to 4 for the problem of fiscal policy uncertainty, and then invited the leaders or owners of enterprise to conduct a survey interview. It is scored according to their intuitive perception of fiscal policy uncertainty. Accordingly, the score of the questionnaire was used as a kind of measure of fiscal policy uncertainty. In response to the uncertainties in the process of economic development, the China Economic Research Center of Peking University began to implement the "Langrun Forecast" project in 2005 and selected 20-40 economic forecasting agencies to investigate their predicted value of GDP for the next quarter. The statistics would be released quarterly after counting. The index was used by scholars such as Ji et al., (2018) and Zhu (2017) after taking the mean or variance in the study to measure the uncertainty of economic policy. Besides, Bloom (2009) used the experts' forecast statistics on output and other macro data released by the Federal Reserve Bank of Philadelphia as a source of statistics and standardized the data. Lastly, the standard deviation was used to measure the uncertainty of economic policies.

\section{The review of various calculation methods}

The measurement of the policy uncertainty indices which is done by scholars at home and abroad has expanded the paradigm of macro-policy research and provided a new perspective for the study of policy uncertainty. On the one hand, compared with other measurement methods, the use of economic variables to construct models to build models to measure economic policy uncertainty is more intuitive, whereas time sequence model's estimation requires sample data of longer interval to obtain more reliable estimation results. However, it is difficult for most of China's macroeconomic variables to meet the above requirements. On the other hand, in the era of big data, due to the very fast speed of newspaper news and website's update, resulting in a large workload of word's capture, it requires multiple repeated searches. Meanwhile, for some key policies, there will be a series of phenomena including the multiple releases of same news and repeated broadcast and so on. It also cannot be technically processed during the process of word's capture and then leads to errors in the calculated indices. As a result, questionnaires based on the behavior subject and the selection of keywords from newspaper news or websites have a strong subjective, which may cause some errors during the process of the measurement of the uncertainty indices.

\section{The design and calculation of the uncertainty indices of educational financial policies}

For the measurement of the policy uncertainty indices, domestic and foreign scholars mainly focus on macroeconomic policies or fiscal policies, and there is no literature to construct and analyze the "uncertainty" indices of the Chinese education field, especially the education fiscal policy. Because of the important role of education fiscal policy in the process of allocation of education resources, this work attempts to construct an uncertainty index for education fiscal policies and to measure it in various ways. According 
to their methods, this paper first selects three newspapers, namely, "People's Daily", "Guangming Daily" and "China Education News", of which "People's Daily" and "Guangming Daily" are the authoritative paper media in the country, which are the party and the government. The mouthpiece has the advantages of wide coverage and strong continuity.

\section{The construction of uncertainty indices}

Baker et al., (2016) in the process of constructing China's economic uncertainty indices, mainly focused on the South China Morning Post in Hong Kong, China then took it as the main source of the capture of words information. According to their methods, this work selects three newspapers at first, namely, People's Daily, Guangming Daily and China Education News, of which People's Daily and Guangming Daily are the authoritative paper media nationwide, which are also the mouthpiece of the party and the government and have the advantages of wide coverage and strong continuity. On the contrary, China Education News is the most influential newspaper in the domestic education field. It has significant professional advantages and a political tendency that is lower than the previous two. To avoid the problem which is proposed by some scholars (Zhu, 2017) of excessive political tendency caused by the newspaper's choices and at the same time improve the professionalism of the indices calculation in the field of education, this work selects China Education News, which has the lowest political in the process of constructing the education financial uncertainty indices as the main source of word's capture. Secondly, in terms of the interval of indices measurements, with the establishment and improvement of China's public financial system in the early twenty-first century, education services were included in the scope of public financial guarantee with "public demand" as the guides. In 2001, the reform of the fiscal policies which promote "county-based" has pointed out the direction for addressing the "offside" and "absence" of China's education finance investment since the tax-sharing system started and finally the education finance is moving towards the 2.0 era. Therefore, based on the reform of educational finance policies since the twenty-first century, this work selects all the papers published in the People's Daily, Guangming Daily and China Education Daily from January 1,2001 to December 1,2018 through the newspaper information database in China national knowledge internet. ${ }^{8}$ Consequently, according to the year, the Education Finance Policy Uncertainty Index is finally calculated with

\footnotetext{
${ }^{8}$ In the processing of media data, this work used the counter module of Python3.7 software to grasp the big data of the official websites of three newspapers including People's Daily. However, due to the large amount of lack of data in some years on the official website of the newspaper and poor continuity of word's acquisition, China national knowledge internet database was used to carries out word's capture.
}

the selecting and standardizing of related words of education finance. For the specific calculation formula, this work revises the methods of scholars such as Baker et al. (2016), Bloom (2014) and Zhu (2017) and constructs the calculation formula as follows:

$\overline{m a v}=\frac{\sum_{i=1}^{n} w f_{i}}{n}$, smav $=\frac{100}{\overline{m a v}}, E F P U_{m}=w f_{i} * s m a v$
$E F P U_{y}=\frac{\sum_{i=1}^{n} E F P U_{m}}{12}$

$E F P U_{t y}=\frac{1}{W_{r}} E F P U_{r y}+\frac{1}{W_{g}} E_{F P U_{g y}}+\frac{1}{W_{e}} E_{e P U_{e y}}$

Among them, $E F P U_{t y}$ in formula (2) represents the weighted total annual education fiscal policies uncertainty indices, which consists of three parts, $E F P U_{r y}, E F P U_{g y}$ and $E F P U_{e y}$ that, respectively, represent the annual education fiscal policies uncertainty indices of People's Daily, Guangming Daily and China Education Daily. Besides, the calculation of the indices of the three newspapers is mainly done by formula group (1), where $w f_{i}$ represents the frequency of uncertainty in education fiscal policies, namely, the number of occurrences of a certain term representing the uncertain characteristics of education fiscal policies. On the other hand, $n$ represents the total number of months in the measurement interval. The measurement interval in this work is from January 2001 to December 2018, so the value range of $n$ is $i=1-216$. Smav represents the monthly average of the uncertain frequency of education and fiscal policies, $\frac{1}{W_{r}}, \frac{1}{W_{g}}$ and $\frac{1}{W_{e}}$ denote the weighted index of three newspapers, respectively. Finally, after standardization while $E F P U_{y}$ stands for the annual education and fiscal policies uncertainty indices after weighting.

\section{The measurement and capture of words}

In terms of word's selection that represents uncertain characteristics of policies, Baker et al.(2016) selected core phrases such as "uncertain", "economy" and "fiscal" in each module which were based on "uncertain", "economy" and "policy". On the contrary, in Chinese newspapers and periodicals, such expressions as "uncertainty" rarely appeared in policy texts or news content. The direct tools for education finance policies to convey uncertainty are education finance funding and education finance policy reform. Therefore, this work selected two modules of "education financial expenditure" and "education financial policy" which emphasized some words that could cover the issues of policies uncertainty, including fiscal educational expenditure, education expenditure reform and education expenditure responsibility and so on. The specific phrase's selection is presented in Table 1: 
Table 1 The selection of uncertain phrase and reasons

\begin{tabular}{lll}
\hline Uncertainty Modules & The Selection of Words & The Reasons of Selection \\
\hline Education Fiscal Funding & Public education expenditure & Core words of education finance \\
& Fiscal educational expenditure & Permanent indices of education finance \\
& Average student expenditure & Permanent indices of education finance \\
& Funding for education & Educational funding component \\
& Public funds for education & Educational funding component \\
& Education personnel funding & Educational funding component \\
Education Fiscal Policies & Education funding reform & Education finance reform vocabularies \\
& Educational transfer payments & The vocabularies of hot topics about education policies \\
& Education expenditure responsibility & The vocabularies of hot topics about education policies \\
& & Hot topics about education finance reform
\end{tabular}

Due to the monthly data collected, this work first conducts a knowledge graph analysis based on the relevant newspapers and literature on education finance in CNKI, and then selected from more than 50 groups of words which is relevant to education finance. Finally, it grasps words whose times of appearance bigger than the total number of months. In addition, due to the lack of information from the China Education Daily in the CNKI from 2017 to 2018, the current data are compiled from other academic search tools such as "Reading Show"

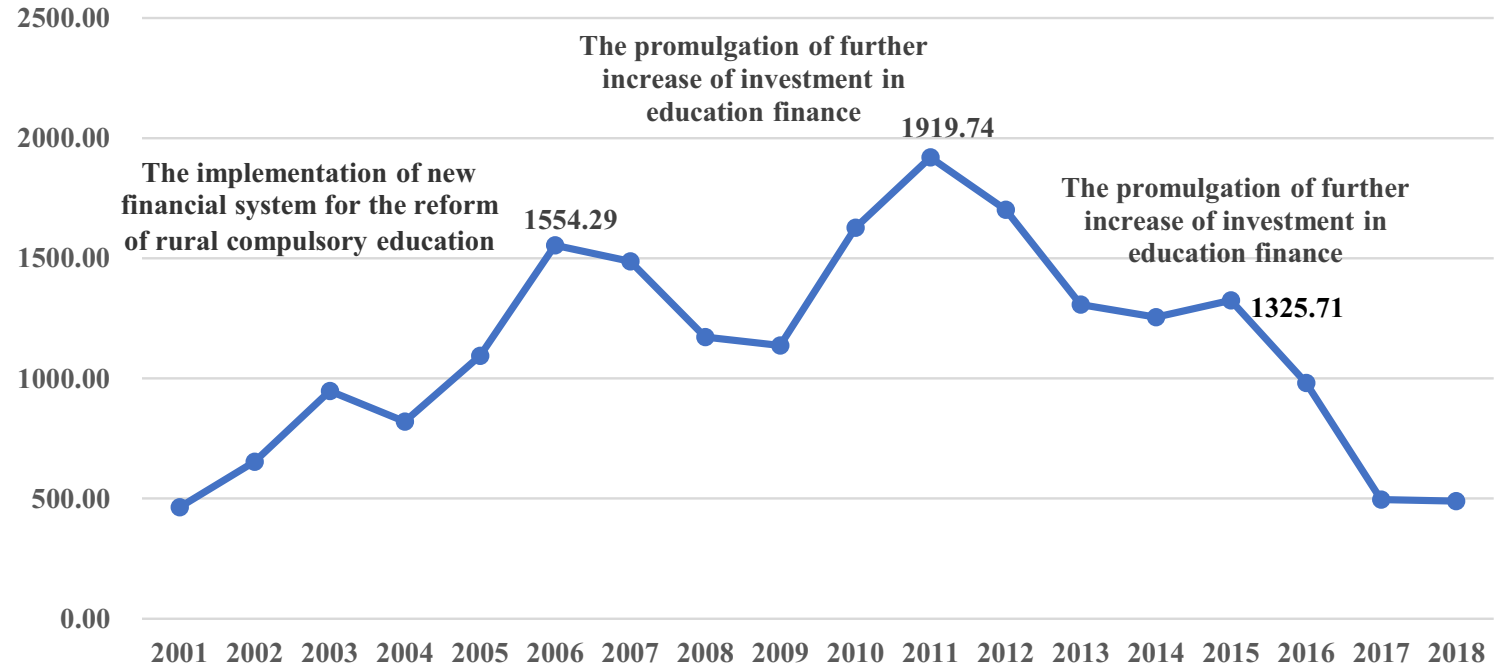

Fig. 2 Trend Chart of China's Uncertainty Indices of Education Fiscal Policy from 2001 to 2018

Based on more than 100,000 pieces of news information in three newspapers such as People's Daily, this work sets up uncertain phrases according to Table 1 and grabs 53,928 times from the news information. Among them, relevant news information appeared in People's Daily for 15,590 times, Guangming Daily for 12,228 times and
China Education Daily for 26,164 times. Therefore, the weighted indexes of the three newspapers were $28.88 \%$, $22.65 \%$ and $48.47 \%$, respectively. The trend chart of the uncertainty indices of China's education fiscal policies over the years that is calculated according to formula group (1) and formula (2) is as presented in Fig. 2: 
Fig. 3 Trend chart of conditional variance of China's fiscal education funding over the years

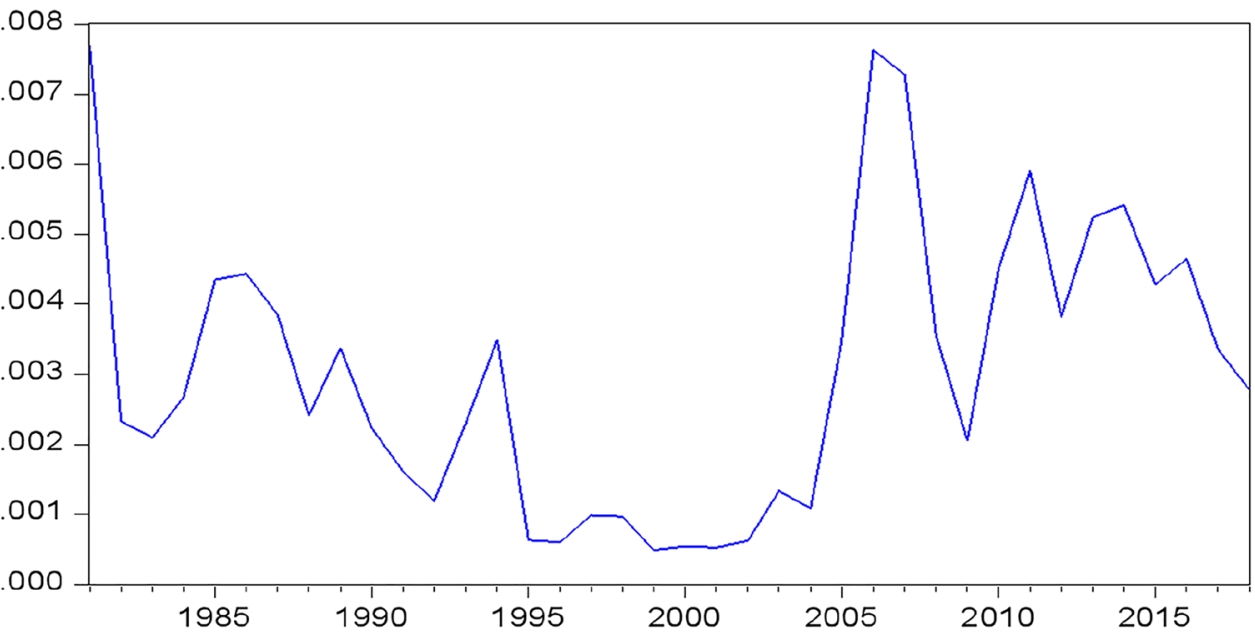

\section{Robustness test and analysis of indices' fluctuation characteristics}

For the uncertainty indices of education fiscal policies measured by the method of word's capture, this work follows the regression model measurement method which was constructed by scholars such as Fatas (2013) and Bloom (2009) in the process of robustness test and attempts to use the GARCH model for re-measurement. Lastly, an exponential feature analysis is performed after matching the regression results with the results of word's capture.

\section{The test and matching of robustness}

In the aspect of data selection of the model, since the GARCH model has higher requirements for time series data, this part selects the national fiscal educational expenditure from 1980 to 2018 as the measurement sample, whose research interval is longer than the method of word's capture. In terms of the use of the model, the GARCH model increases the conditional variance of the disturbance term compared with the traditional ARCH model and relaxes the restrictions on the parameters thus to better address the problem of conditional heteroscedasticity. On the other hand, this part is further extended on this basis, using the EGARCH model, which further relaxes the GARCH model's non-negative coefficient limitation and expands the scope of application.

According to the software Eviews10, the model is constructed. In order to make the time sequence data smooth, this work performs logarithmic first-order difference processing on the fiscal educational expenditure to obtain the logarithmic fiscal educational expenditure growth rate $r$. After the test of ADF unit root, results at the 1\% significance level rejects the hypothesis that there is a unit root. At the same time, the Q-statistic correlation test shows that there is no correlation among the parameters within r. Since there is no obvious correlation in the sequence, the mean value equation is set to white noise while the model is set to $R_{t}=\pi_{t}+\varepsilon_{t}$. Then, $r$ is de-averaged to obtain the residual $\mathrm{w}$, and let $w=r-0.147735$. The ARCH effect test is carried out through residual squared correlation plot. After comparison, the $\operatorname{EGARCH}(1,1)$ model is established then the ARCH test is performed on the residuals to obtain the F statistics. As a result, it is presented that the $\mathrm{F}$ statistics are not significant, which proves that the ARCH effect has been eliminated and the EGARCH model is well fitted. The measurement results of the uncertainty indices of education fiscal policies are presented in Fig. 3.

The EGARCH model constructed in this work better captures the fluctuation trend of the conditional variance of fiscal education funding in China over the years. As a proxy index for the uncertainty of education fiscal policy (Fatas and Mihov, 2013and Bloom, 2009), There is a significant time-varying volatility in the conditional variance of fiscal education funding. Meanwhile, the amplitude of the volatility also shows a more intense trend. As presented in Fig. 3, the peak volatility of this index has appeared in several intervals since 2001, such as 2005-2006, 2011-2012, and 2015-2016, which basically reflects the major events, the promulgation of important education fiscal policies or changes which are brought by pilot or modification. At the same time, through comparing the change trend of the indices in Fig. 2 and Fig. 3, the fluctuation trend and the peak value of the indices measured by the two methods in the same time period can basically match, which provides that the measurement results that are constructed by this work based on the method of word's capture that was designed by the Baker et al. (2016) have passed the robustness test. The measurement results also have good reliability. 


\section{The analysis of index volatility characteristics and causes}

For the education finance uncertainty indices calculated by two methods, this work matches the measured uncertainty indices with the fluctuation of macro education finance policies and finds that its calculated indices of education finance policies is uncertainty also peaked accordingly after the issuing of important education finance policies. Consequently, it shows a high degree of agreement between this two.

First of all, in 1993, China implemented the financial reform of management system, focus on adjusting tax income distribution between the central government and local government, the centre of the fiscal revenue up to a certain extent, result in local government routine power and financial power not match, the local government financial input in education of responsibility is not clear and education expenditure does not reach the designated position phenomenon (Gu, 2012). In response to the above problems, China issued a series of education financial policies which had a meaning of landmark from 2005 to 2006. For instance, in 2005, the State Council issued the Notice on Deepening the Reform of the Rural Compulsory Education Funds Guarantee Mechanism, then it gradually began in the spring semester of rural primary and secondary schools in 2006. In this respect, this policy re-divided the rural education financial sharing mechanism and formed a historical breakthrough in the reform of the education financial policy, resulting in fundamental changes in China's education financial system after 2005. During this period, the uncertainty indices of China's education fiscal policy fluctuated violently. And reached the first peak in the measurement interval eventually in 2006. On the other hand, this stage is also a peak period of the introduction and construction of education fiscal policies under the background of stable and rapid growth of China's education fiscal investment after the founding of the People's Republic of China.

Secondly, since the 21th century, the Chinese central government set the strategic goal of "fiscal educational expenditure for $4 \%$ of the GDP" aim has been on the agenda again, urged governments at all levels to increase financial input in education, $4 \%$ of the target can be realized at an early time. Under this background, from 2010 to 2012, the State Council issued the Opinions on Further Increasing Financial Investment in Education, which strengthened the responsibilities of governments at all levels in education financial input from the policy level. Since then, the Ministry of Finance, the National Development and Reform Commission, the Ministry of Education and other departments had successively issued fiscal policies on pre-school education, compulsory education and rural compulsory education. Accordingly, those education fiscal policies have formed a three-dimensional policy system. Under the constant supervision of a series of policies which had a meaning of resource mobilization, China's fiscal education expenditure accounted for and exceeded 4\% of GDP in 2012, which has achieved long-term policy goals. After the release of the policy bonus of $4 \%$ in education finance at this stage, the lack of clear top-level policies design for education finance investment led to constant intensification of the uncertainty problems brought by the empty window period (Wang et al. 2017). During this period, China's education finance policies uncertainty indices once again entered the stage of severe fluctuations and reached a historically high value within the measurement range in 2011.

Thirdly, For a long period of time in China, public finance was viewed as serving the government and authorities. Such a perspective started to change in the early 2010s, which has been reflected in major government policies and regulations. Under this background, the National People's Congress revised and perfected a series of important legal texts such as the Education Law of the People's Republic of China in 2015. Besides, the State Council has formulated a series of normative documents related to financial investment in education, including the Notice on Further Improving the Guarantee Mechanism for Compulsory Education Funds in Urban and Rural Areas in 2015. Through the issuance of the above-mentioned legal texts and policy documents, China ha basically completed the division of responsibilities between the government and the market, as well as governments at all levels in the process of educational resource allocation, and education policies at all levels have been basically determined at this stage (Wang \& Tian, 2018). At this stage, the uncertainty indices of China's education and fiscal policies showed its third peak, and the peak and indices fluctuations were slightly smaller than the previous two stages. It is foreseeable that in the process of ushering in the era of education finance 3.0, along with the division of intergovernmental education finance responsibilities, the adjustment of the internal structure of education finance funds and the realization of a high level of balanced education investment, all of these require the government to formulate, modify, or improve a series of relevant policies thus to lead to a large fluctuation in the uncertainty indices of the education fiscal policies and restore to a high level of operation.

\section{Summary}

Based on the evolution of China's education fiscal policy since the twenty-first century, this work uses Python3.7 to select all the papers published in the People's Daily, Guangming Daily and China Education Daily from January 1,2001 to December 1,2018 through the newspaper information database in China national knowledge internet and improves Baker et al. (2016)'s formula for measuring the 
policy uncertainty index. Consequently, according to the year, the Education Finance Policy Uncertainty Index is finally calculated with the selecting and standardizing of related words of education finance. Our findings reveal that the uncertainty indices are highly consistent with the fluctuation of education fiscal policy in various stages in China.

The academic contributions of this study are as follows: on the one hand, the uncertainty caused by the change of education financial policy is incorporated into the study of education resource allocation, which opens up a new perspective of education policy research; on the other hand, in the process of constructing the uncertainty indices of China's education financial policy, we correct the selection errors and omissions in Baker et al (2016)'s study, and ensure the reliability of the indices measurement results; finally, this article provides a theoretical basis for China and even other countries in the Asia-Pacific region to develop and improve education fiscal policies and counterbalance the uncertainty influence caused by the COVID-19 epidemic, trade disputes and macroeconomic cycle in the process of education resource allocation.

\section{The countermeasures and recommendations}

Zeng and Ding (2010) has summed up the changes in China's education policy since 1949 and believed that the uncertainty of education policies affected the development of China's education. The development of uncertain issues in education fiscal policy, especially the emergence of indices peaks, may have a significant negative impact on the long-term stable growth of fiscal education funding. With the "new normal" of China's economic development, the uncertainty of education and fiscal policies has developed normally. Therefore, government departments should attach great importance to the uncertainty of education fiscal policies. On the one hand, in the process of policies' intervention of resource allocation, the reasonable boundary of the "tangible hand" should be scientifically defined to return it to the function of macro-control. On the other hand, in the process of carrying out policy changes, policies' innovations or experimental subsidy, it ought to try to reduce or control uncertainties as much as possible, thereby reducing the negative impact of education fiscal policies uncertainty on government expenditure. Finally, due to the process of extensive demonstrations, expert discussions and public suggestions and so on before the implementation of relevant education fiscal policies, the introduction of policies has been "compromising" then led to increased uncertainty. Consequently, government departments can use strict budget constraints to reduce the negative impact of policies uncertainty on education investment and harden education budget constraints (Fatas and Mihov, 2013).

\section{The outlook of the research}

In the "new era" government departments frequently change education finance and even macroeconomic policies, which indicates that in the process of China's transition to a full market economy model, government departments still have strong willingness and ability to intervene in the allocation of education resources and economic operation. Before a policy is introduced, the relevant behaviour subjects often predict according to the policies content obtained from themselves or from the outside world, and then assess the influence after the implementation of new policies thus to adjust their various behaviors from the perspective of maximizing benefits. In conclusion, as a systemic risk faced by market actors, the uncertainty of education fiscal policies and even economic policies has inevitable characteristics, which will have an important impact on the macro and micro actors in the education field, and will also bring a lot of blanks for the research about uncertainty issues.

From the dimension of macro research, with the global trade war launched in 2017 and the COVID-19 epidemic in 2020 , what impact will the uncertainty of macroeconomic policies have on education investment? In the context of the increasing policy uncertainty, does economic uncertainty inhibit or promote the growth of education expenditure? Does it have a heterogeneous influence on the internal structure of funds? On the other side, from the micro-research dimension, what kind of influence will the increase in the uncertainty of education fiscal policy and even economic policy have on family education investment decisions? Are families more willing to make savings, invest in financial management projects or invest in education? Is there a heterogeneous effect on households in different regions? Lastly, this work only measures the total policy uncertainty indices of education finance. However, What are the characteristics of the education finance policy uncertainty indices of different education levels and different regions? These issues have strong practical significance and will eventually become a topic of research in the field of educational finance research in the future.

Acknowledgement This work was supported by National Natural Science Foundation of China (No. 71704073) and the Key Entrusted Project of Jiangsu Social Science Foundation (No. 20WTA00).

Funding The authors are grateful for the Major Project of National Social Science Fund of China (No. 19ZDA116), the National Natural Science Foundation of China Youth Science Fund Project (No. 71704073) and the Key Commission Projects of Social Science Foundation of Jiangsu Province (No. 20WTA001). 


\section{References}

Albuquerque, B. (2011). Fiscal institutions and public spending volatility in Europe. Economic Modeling, 28(6), 2544-2559.

Ali, A. M. (2005). Fiscal policy and economic growth: The effect of fiscal volatility. Journal of Business \& Economics Research, 3(5), $17-26$.

Angus, M. (2017). Measuring economic uncertainty and its effects. Economic Record, 93(303), 550-575.

Baker, S., Bloom, N., \& Davis, S. (2016). Measuring economic policy uncertainty. Quarterly Journal of Economics, 131(4), 1593-1636.

Bloom, N. (2009). The impact of uncertainty shocks. Econometrica, $77(3), 623-685$.

Bloom, N. (2014). Fluctuations in uncertainty. Journal of Economic Perspectives, 28(2), 153-176.

Born, B., \& Pfeifer, J. (2014). Policy risk and the business cycle. Journal of Monetary Economics, 68, 68-85.

Chong, A., \& Gradsteing, M. (2009). Volatility and firm growth. Journal of Economic Growth, 14(1), 1-25.

Fatas, A., \& Mihov, I. (2013). Policy volatility, institutions and economic growth. Review of Economics \& Statistics, 92(2), 362-376.

Frank, H. K. (2006). Risk, Uncertainty and Profit. . Dover Publications.

Gong, M., Gan, J. W., \& Cai, J. (2018). Uncertainty of tax policy and regional economic fluctuations-An empirical test based on China's municipal panel data. Journal of Yunnan University of Finance and Economics, 34(3), 13-24.

Gu, J. F. (2012). Spatial dynamics and determinants of county-level education expenditure in China. Asia Pacific Education Review, 13(4), 617-634.
Ji, Y., Wang, X., Tan, Y. Y., \& Huang, Y. P. (2018). Uncertainty in economic policies, implicit government guarantees and differentiation of corporate leverage ratios. Economics (Quarterly), 17(2), $449-470$.

Jurado, K., \& Ludvigson, Ng. (2015). Measuring uncertainty. American Economic Review, 105(3), 1177-1216.

Steven, J. D., Ding, Q. L., \& Xu, G. S. (2019). Economic policy uncertainty in China since 1949: The view from mainland newspapers. Working paper.

Wang, D., Zhang, Q. W., \& Huang, B. (2017). Design and standardization calculation of the adequacy indices of China's educational finance. Xinhua Digest, 17, 117-120.

Wang, L. Y., Zhu, W., \& Guo, H. M. (2015). Uncertainty research on local government fiscal revenue and expenditure: Taking Beijing as an example. Urban Development Research, 22(4), 1-5+20.

Wang, R., \& Tian, Z. L. (2018). Meeting the era of education finance 3.0. Education Economic Review, 3(1), 26-46.

Zeng, M. C., \& Ding, X. H. (2010). Efficiency, fairness and adequacy: China's compulsory education fiscal policy. Peking University Press.

Zhu, J. (2017). Indices construction, characteristics and incentives of uncertainty in China's fiscal policy. Finance and Trade Economics, 38(10), 22-36.

Zhu, J., \& Cai, T. T. (2018). Uncertainty of China's fiscal and monetary policy and inflation expectation-an empirical analysis based on the uncertainty index of China's fiscal-monetary policy. Fiscal Research, 1, 53-64.

Publisher's Note Springer Nature remains neutral with regard to jurisdictional claims in published maps and institutional affiliations. 